\title{
POSTDICTADURA, VANGUARDIA Y ESCENA CULTURAL
}

\author{
Federico Galende
}




\section{FEDERICO GALENDE}

Politólogo, filósofo, teórico del arte y escritor. Doctor en Filosofía, miembro del Doctorado en Filosofía con mención en Estética de la Universidad de Chile y Profesor Asociado del Departamento de Teoría del Arte de la misma Universidad. Colabora en los medios The Clinic, El Desconcierto y Revista Santiago, y ha publicado varios libros, entre los que destacan recientemente la novela Me dijo Miranda, 2013; Vanguardistas, críticos y experimentales. Vida y artes visuales en Chile, 2014; Comunismo del hombre solo. Un ensayo sobre Aki Kaurismaki, 2015; La República perdida, 2016; Memorias de octubre, 2017; e Historia de mis pies, 2018. Se encuentran actualmente en reedición Rancière. El presupuesto de la igualdad en política y en estética (Eterna Cadencia, 2019); los volúmenes I, II y III de Filtraciones. Conversaciones sobre arte en Chile (Alquimia, 2019); y Modos de producción. Ensayo sobre arte y trabajo (Palinodia, 2019). Ha sido profesor visitante de las Universidad de Duke, de Aberdeen, de Tulane y este último año de la Universidad de Michigan. 


\section{POSTDICTADURA, VANGUARDIA Y ESCENA CULTURAL}

La palabra postdictadura contiene una ambivalencia en el sentido de que proyecta una sombra de intranquilidad en lo que a la vez señala como pasado. Con esto apunta a una especie de advertencia, como si la catástrofe que se yergue por detrás suyo (tras ese prefijo) llamara a comprender el presente en calidad de condicionado. Esto significa que habita en ella -en esta palabra- una carga melancólica, una rémora de inmovilismo, de modo que la lógica del terror que evoca se prolonga por encima de sí misma e impone así una cautela a la construcción de un verdadero proyecto democrático. Este reparto, esta tensión, están a la base de lo que llamamos "transición".

La transición, cuyo desenlace parece mantenerse a perpetuidad en suspenso, partió a la vez como una pugna entre diversas fuerzas por dar positividad a un no pronunciado por la mayoría del pueblo. En el año 1988, cuando la dictadura llevaba quince años en el poder y el pueblo cansado, exhausto y perseguido, dijo que no, se inició un nuevo drama histórico, en parte debido a que un no es un acto en sí mismo, un comienzo colmado de sí que no necesariamente traza un continuum nítido ni diagrama un futuro que opere en una dirección única.

La historia del pensamiento, pero también la de la literatura o la crítica han tratado, a lo largo de los siglos, las subrepticias apariciones de estos no que caracterizan a los pueblos. Y también a los seres. En El hombre rebelde, por poner un ejemplo, Camus se valió de una fórmula bastante sucinta: "el hombre rebelde es el hombre que dice no". Pero nunca se preguntó -ni convirtió tampoco en un dilema de su intriga existencialista- qué podía seguir después de este no en el que la propia existencia, la propia vida, estalla con la potencia de un rasgo único que traspasa al sujeto. Esto, a tal punto que se podría perfectamente afirmar que en el relámpago o en el destello de un no, el sujeto se limita a ser una suerte de espectador pasivo, un mero anónimo a la espera de una configuración operada por un enunciado que fue sin él. Dicho en breve, no es el sujeto el que dice no, es más bien el no declamado en la hondonada nocturna de la consciencia el que determina retrospectivamente al sujeto.

Encontramos un caso emblemático en Hamlet, de quien Derrida se tomó premonitoriamente en Espectros de Marx para exhibir cómo, tras la caída del Muro de Berlín, una parte considerable del imaginario letrado de Occidente se precipitaba en una línea similar a la que estamos aquí tratando- a celebrar el fin del marxismo, el del socialismo, el fin de los grandes relatos y el de casi todo, bajo el ciego impulso de 
una manía triunfante ${ }^{1}$. The time is out of joint. O, cursed spite, that ever I was born set it right, exclama Hamlet, negando en un acto la demanda por vengar la muerte de su padre y resistiéndose a la suerte de tener que ser él quien venga a enderezar, a restituir o ejercer el derecho en el corazón de un tiempo fuera de sí o de una época deshonrada.

Se pueden hacer muchas conjeturas sobre el no de este príncipe atribulado y exhausto, ponerlo a cuenta de la relación edípica con su madre, como lo intentó Freud, o conducirlo a una teoría sobre la irreductibilidad de la justicia al derecho, como lo intentó Derrida, pero lo cierto en que el no de Hamlet es simplemente un no. Uno muy similar al que en un orden más colectivo pronuncia el Mariscal Tito en 1948 ante la propuesta del pacto con Stalin. Tito dijo no, pero cacaso sabía lo que estaba diciendo? ¿Tenía una mínima idea de las consecuencias que este no arrojaría sobre el destino de una Yugoslavia unificada? La respuesta es difícil y tal como más de una vez fue mencionado, es altamente probable que el desastre de los Balcanes se deba a los diversos intentos, a las diversas pugnas y luchas encarnizadas por dar positividad a ese no que en un rapto instantáneo dejó caer sobre la tierra uno de los destinos más promisorios del comunismo.

Tras esta pequeña elipsis, en la que el acto de negar parece prescindir por igual de un ayer y un futuro, podemos regresar a Chile, al año 1988, donde el no fue proclamado por una mayoría - no por un príncipe singular, no por una heroína estrafalaria- que aspiraba de una vez por todas a vivir en una sociedad democrática. Pero ¿qué es una democracia? La democracia no es un objeto, no es una cosa, ni siquiera es, hablando con precisión, un régimen de gobierno o un régimen político; la democracia es una forma social al interior de la cual confluyen diversas fuerzas, diversas perspectivas e imaginarios en pugna por una definición. Por eso señala Lefort con razón que la democracia no es nunca un objeto que tenga una significación última ${ }^{2}$. Esta lucha incluye, y a la vez asimila, las distintas maneras que tiene un no de ser traducido a una determinada articulación política.

En el caso específico de nuestra transición, se tendría la impresión de que este no inicial fue traducido a la continuación de una revolución capitalista que consistió básicamente en consumar, a partir del terrorismo de Estado y la ley de la fuerza, la desregulación radical del régimen de acumulación burgués. Esto, en un contexto en el que el no aglutinó, como no podía ser de otro modo, una serie heterogénea y transitoria de causas múltiples, en circunstancias en las que una articulación pertenece por naturaleza al reino del uno.

1. Ver Derrida, Jacques, Espectros de Marx, Trotta, 2012.

2. Ver Lefort, Claude, La invención democrática, Nueva Visión, 1996. 
La lucha entre ricos y pobres, como más de una vez observó Rancière ${ }^{3}$, no se agota en la contradicción entre los propietarios de los medios de producción y las fuerzas productivas sino que, por el contrario, la se engloba en una lucha más amplia: la lucha entre la multiplicidad y el uno, entre las causas que son heterogéneas al interior de una rebelión y la unidad con la que el poder articula verticalmente un proyecto político. Precisamente por esto tampoco el pueblo es algo en sí mismo, una unidad definida o un objeto que tenga una identidad, a excepción de que se lo defina como aquello que es heterónomo al poder de las categorías o de las designaciones.

Lo anterior explica que lo que llamamos transición sea el producto de un no traicionado por la afirmación de una clase política que se involucró en la gestión de una institucionalidad extremadamente condicionada. Esto, fundamentalmente a causa de que los sectores supuestamente progresistas que estuvieron a cargo de la gestión política y la administración del proyecto de la democracia son parte de una clase política que dejó en el pasado la más mínima sombra sobre sí misma para resignarse a lo que concibió como un nuevo realismo político. Desde los primeros años del gobierno de la Concertación, este realismo consistió básicamente en desechar las reivindicaciones más elementales y las más legítimas demandas del pueblo bajo el pretexto de que había que "cuidar la democracia".

El problema está en que la idea de este cuidado, chantajista y amenazante por donde se lo mire, pasó por alto el hecho de que también el realismo tiene en el campo de la política una doble acepción. Se puede entender por realismo (y no pocos lo hacen) la asimilación conformista de una realidad predeterminada que traza de antemano las condiciones de lo que es y no es posible. Pero el realismo, tal como lo postuló Maquiavelo en los umbrales de la modernidad política y como lo reinterpretó Gramsci en sus notas escritas en la cárcel de Mussolini, quiere decir también algo completamente distinto: significa sencillamente la autoconsciencia de que no existe una realidad independiente del poder o la fuerza, de forma tal que una realidad siempre está hecha. Para saber cómo está hecha hay que partir necesariamente de esta evidencia, una que la vuelve a la vez, por esto mismo, maleable, transformable, etc.

Realismo, para decirlo en breve, significa que todas las prácticas, sean de carácter artístico, literario, coreográfico, discursivo o decisional, participan e inciden en la producción de la realidad. Esta es la razón por la que un autor como Erich Auerbach se propuso en su libro Mimesis mostrar cómo la literatura de Europa, lejos de limitarse a ser un comentario más acerca de la facticidad histórica, estuvo plenamente implicada en la construcción misma de la historia ${ }^{4}$. Algo que, dicho de

3. Ver Rancière, Jacques, El desacuerdo, Nueva Visión, 2007.

4. Ver Auerbach, Erich, Mimesis. La representación de la realidad en la literatura occidental, FCE, 1986. 
paso, ayuda a comprender mejor por qué el arte, la literatura o la ficción no son meros pasatiempos de una clase letrada o añadidos decorativos del mundo, sino procesos complejos que están a la base de la inacabada construcción de la realidad.

La odiosa contraofensiva con la que la derecha global teje hoy una realidad en la que el incremento del gasto público distrae recursos de la inversión o en la que la reducción del salario de los trabajadores cada vez más pobres será compensada a futuro por el crecimiento económico, también debió (y debe) se analizada como una fuerza involucrada en la producción de la realidad política. Esta realidad política, asimilada con total irresponsabilidad y negligencia desde los primeros años de la transición, tiene también su historia y responde al hecho de que la burguesía advino a la modernidad con una revolución inconclusa, pues cuando logró quitarse por fin de encima los obstáculos que a su régimen de acumulación le imponía el modo de producción feudal, se encontró con los obstáculos que a ese mismo régimen comenzó a imponerle la institucionalidad democrática y el debate público acerca de la distribución de los ingresos. De allí en adelante, el proyecto de la derecha no consistió en otra cosa que en alcanzar la liberación radical de su lógica de acumulación.

Sabemos que de esta liberación, de esta revolución consumada por la burguesía financiera transnacional, el Chile de los años '80 fue el más sofisticado de los laboratorios, de manera tal que también el concepto de transición adoptó una doble acepción. Se supone que por un lado remite al tránsito que va de la dictadura a la democracia, pero por otro remite al tránsito que va del Estado al mercado ${ }^{5}$. Ambas definiciones deben ser puestas a la vez en relación con la ambivalencia que atesora la palabra realismo. ¿Por qué? Porque la noción de realismo que en definitiva escogió la izquierda renovada que estuvo a cargo del proceso transicional no fue en absoluto inocente y responde, incluso, a un programa de institucionalización y estabilización de la revolución capitalista acontecida durante los años '80.

La consecuencia de esto fue entonces que la transición debutó tensionando al interior de un mismo proyecto tres fuerzas reconocibles y a la vez diversificadas: la de una izquierda muy tenue que conquistó el poder bajo la promesa de administrar el capitalismo mucho mejor que los propios capitalistas; la de un campo cultural que tras pasar por el experimento de las vanguardias de los '60 terminó resignando las prácticas del arte y de la crítica a un testimonio atribulado sobre la catástrofe irreversible que se yergue por detrás de nosotros; y la de un pueblo múltiple y heterónomo que quedó completamente excluido del proceso de toma de decisiones de la supuesta democracia representativa.

Dado que el pueblo es siempre una resta (una resta categorial, pero también, como dice Rancière, la parte de los sin parte en la esfera de lo común), concentrémonos en

5. Ver Thayer, Willy, La crisis no moderna de la universidad moderna, Cuarto Propio, 1996. 
lo que ocurrió a nivel de la representación. Esto, en virtud de que si los problemas del arte, la crítica, la política o la teoría confluyen en este asunto, el de la representación, es porque se trata de una noción que no cambia cuando pasa de una lengua a otra. Un artista es un ser habitado por un conjunto de sensaciones sin forma que buscan ser objetivadas en una determinada forma sensible. Llamamos obra de arte a esta objetivación sensible. Pero a la vez una articulación política es eso que emplaza en la esfera de lo común una multiplicidad no organizada, no ordenada. La crítica, la teoría o la filosofía no se comportan de distinta manera: una crítica, un teórico, una filósofa articulan conceptualmente y ponen en representación un múltiple de problemas que admiten diversos órdenes.

Toda representación, naturalmente, deja algo fuera, es incompleta, imperfecta, pero por este mismo motivo se mueve o se transforma en relación a una presencia sentida que nunca es captada en su totalidad.

Sin embargo, y con toda probabilidad a causa del escepticismo y la melancolía reinantes durante la dictadura, la transición se inició confrontando dos formas extremas del representar. Por un lado, el campo de las humanidades y de la cultura crítica pareció imponerse a sí mismo una resta absoluta de representación. A título del horror, del terror y la presentación de lo impresentable, el imaginario crítico de la izquierda cultural tendió hacia el grado cero de la representación, de forma tal que sus prácticas, sus discursos y modos de hacer se desarrollaron a partir de un imperativo fundado en el desplazamiento de los signos, la desnarrativización del sentido y la producción de imágenes o textos en los que lo indecible testimonió en tanto ausencia. Por otro lado, los partidos de la Concertación llevaron la representación a un extremo a cuya altura no pudieron estar.

Esta resistencia a la representación y esta representación prometida pero incumplida tuvieron su contrapunto temprano en la herencia de un campo cultural derivado de la neovanguardia de los ' 80 -la del arte conceptual, la asimilación de la crítica postmoderna y la escena de avanzada- y la herencia del campo de las ciencias sociales, interpretado prioritariamente por los miembros del grupo FLACSO. No obstante, y a pesar de la diferencia, primó en ambos casos un relente de vanguardia letrada. Para cualquiera resulta evidente que prácticas performáticas como las de quemarse una mejilla, pasarle la lengua a un mendigo o vomitar en plena Bienal de París una torta completa parado en cuatro patas, todo debidamente acompañado de textos y catálogos escritos en códice, no tienen en la intervención política su urgencia más inmediata, así como no la tuvieron tampoco las negociaciones llevadas a cabo entre cuatro paredes por parte de las élites de una izquierda renovada.

El tipo de crítica cuyos rasgos fueron designados tempranamente como postmodernos y el plan de recuperación de la democracia ideado por el grupo de intelectuales nacido de FLACSO poseen de todos modos una historia que se 
remonta a los años ' 60 , donde las vanguardias cobraron sentido en virtud de una promesa que afinaba con el contexto de época: la promesa de ver en el horizonte aquello que para la masa iletrada permanecía invisible. Esta promesa, a la vez, se fundó en el logro parcial de devolver el arte a la calle. Esos fueron efectivamente los años de la Reforma Universitaria, de las ferias artísticas, de la construcción de la UNCTAD III, de las pintadas murales, de la Bienal de Grabado, de la vuelta a la Lira Popular, de la nueva canción chilena, del Instituto de Arte Latinoamericano, de los Encuentros de Artistas del Cono Sur, del Museo de la Solidaridad, etc. En ese contexto, las aceleraciones de la historia y la maleabilidad de las condiciones materiales de la existencia hicieron posible el sueño de la construcción del hombre nuevo.

La promesa política libertaria empujó las prácticas del arte hacia un programa de revolución estética consistente en la destrucción de la distancia del arte con el mundo de la vida. Esta promesa, sin embargo, encierra como sabemos un prejuicio, no solo el de que la vida requiere del artista de un modo especial, sino también el de que este no ha recibido las mismas anestesias y alienaciones de los hombres del pueblo, motivo por el que está en condiciones de brindar directrices para la transformación del mundo.

Si este sueño de la vanguardia estética cuenta con una contradicción es en virtud de que el artista suprime la diferencia del arte para confundirse con la vida, pero a la vez hace valer en la vida la diferencia de haber suprimido el arte. En el campo de lo político esto no es muy distinto: se erigen como pastores los seres que a título de una capacidad autoimpuesta entrevén en el horizonte el paraíso salvífico hacia el que deben ser conducidas las masas organizadas.

La promesa estética de la destrucción del arte para la creación del hombre libre y la promesa política de la igualdad en un horizonte al que no tienen acceso los seres comunes son parte de lo mismo: se trata de un espíritu de época, propio de la idea sartreana del artista-intelectual en cuanto responsable exclusivo de la transformación de la vida. Los cuerpos inundan las plazas, los parques, toman las fábricas, marchan en hilera hacia la revolución, pero siempre con alguien delante o detrás en cuya consciencia avezada, eximida de la más mínima alienación, entrevé el camino hacia el gran paraíso. De todos modos, por esos años el ejercicio de la política, que es colectivo, presentó el beneficio de permitir a hombres y mujeres sacar a pasear su cuerpo.

Tras el golpe de Estado y la repentina violencia puesta en escena por la dictadura se disiparon las plazas, se vaciaron las calles, se volvieron un páramo los espacios que antes eran comunes y los cuerpos, acostumbrados antes a extraviarse en una anímica colectiva, retornaron sobre sí mismos. Sin bares, ni camas, ni parques en los que estacionar esos cuerpos, la desdicha se convirtió en moneda corriente y 
trazó un giro en el corazón del arte contemporáneo. Si las calles de Chile habían sido durante la época de las utopías y el sueño del hombre libre, el lugar de una fiesta contestataria en la que prácticas como el muralismo, los festivales de arte o la pintura post-informalista de la vanguardia operaron como un dispositivo de concientización, y si durante los años que siguieron al golpe de Estado de 1973 el arte de corte más contestatario, aglutinado a grandes rasgos bajo el título de escena de avanzada, transportó ese dispositivo hacia un guion teórico más que sofisticado, legible de manera exclusiva para un grupo de especialistas y de entendidos, se diría que con la transición la esfera del arte y de la crítica giró hacia el grado cero de la representación bajo la sospecha de que una práctica o un discurso solo podían limitarse a dar cuenta de que tras la catástrofe no había ya nada que esperar. Esta resta de expectativa, de representación y de espera se tradujo a la vez, como ya dijimos, en una tímida democracia de acuerdos en manos de una clase política que, privada ya de horizonte, terminó por traicionar todo proyecto para abocarse a acuerdos de carácter intracupular y administrar una esfera pública definida por el capital financiero transnacional.

La transición del Estado al mercado fue simultánea si se la piensa desde el campo de la cultura crítica, de una transición que pasó de la arrogancia vanguardista de la creación del hombre nuevo y la promesa transformadora de la totalidad de la historia a una especie de neovanguardia que halló en la biopolítica la configuración de una vida por parte de los dispositivos de poder. A partir del golpe de Estado y en virtud de las abstracciones infinitamente prolijas a las que son propensas las modas académicas, se viajó repentinamente de un imaginario vanguardista para el que la humanidad podía ser diseñada por una clase ilustrada, a un imaginario biopolítico de corte teológico para el que la suerte ya estaba echada. Los defensores de una y otra teoría, antes capaces de manipular con pericia los hilos que cambiarían las cabezas del pueblo y ahora propensos a comunicar a ese mismo pueblo que su destino histórico estaba ya predeterminado, fueron más o menos los mismos, ideólogos que cambiaron sin la más mínima autocrítica su modernismo prometeico y utópico por el fin de la historia y la alineación de la vida. Y del cielo que el progreso y las masas proletarias organizadas tomarían un día por asalto se pasó a este otro cielo configurador de la vida desde las esferas celestes. En definitiva, ni un pedazo de cielo para el hombre común, para la mujer común, para los cuerpos que organizan en medio del cotidiano sus modos de estar juntos.

Estos modos de estar juntos conforman, sin embargo, la única política que realmente importa. Por eso el problema de la filosofía no es el origen misterioso del ser o la determinación vertical de cómo deben liberarse los seres; el problema de la filosofía es cómo se enhebran y desenhebran los cuerpos, las imágenes, los textos y las voces sobre la superficie de un pensamiento en común. 
Curiosamente, el tiempo en el que mejor parece haber sido comprendido este asunto no es el que corresponde a la época de la modernidad utópica o a la época atribulada de la moda biopolítica, sino a un siglo que, como observa Rebeca Solnit, nació atesorando en el planeta una gran cantidad de reivindicaciones, movilizaciones y cuestionamientos a las formas convencionales de las democracias representativas ${ }^{6}$. Los indignados en España, los obreros en Londres, las marchas en Grecia, el pueblo avanzando hacia las plazas en Túnez, en Egipto, en Libia o en Siria, la gente saliendo a las calles en Argentina, etc., partieron resumiendo una protesta a nivel global que dio la impresión de insinuar el derrumbe definitivo del régimen de acumulación implantado por el neoliberalismo.

Y Chile, donde desde el 2010 se venía protestando activamente por la aprobación en Coquimbo de una termoeléctrica que dañaría severamente la flora y la fauna del santuario de la naturaleza de Punta de Choros, por la cicatriz que Hidroaysén proyectaba sobre los milenarios bosques del sur o por el abrupto retiro en Magallanes de las subvenciones al gas, no fue esta vez la excepción. La prueba de que no lo fue reside en la forma singular que adoptó el movimiento estudiantil del 2011, donde las prácticas del arte tendieron a dejar atrás esta dialéctica entre el futuro igualitario proclamado por los pastores de las vanguardias de los '60 y la reversión luctuosa de un arte que se redujo a testimoniar el fin de la historia, para dar lugar a un proceso anónimo y colectivo, a una red colaborativa y conjunta que se movilizó por la causa de la educación haciendo valer la igualdad no ya como una promesa por venir, sino como un presupuesto con el que experimentar.

En esto reside quizás el viraje más importante respecto a cómo había funcionado hasta ahora el vínculo entre arte, cultura y política.

A movimientos de esta naturaleza, a los que habría que sumar la potencia reciente de la movilización feminista a nivel planetario, la derecha global, amparada en la propiedad de los grandes medios y un manejo de la opinión pública que trasciende con creces el trabajo de las redes sociales y los medios alternativos, respondió con una contraofensiva perversa. Hace apenas unos años, el filósofo Slavov Zizek, apoyándose en la división lacaniana entre la verdad simbólica y la verdad imaginaria, señalaba en una entrevista que por mucho que uno no pudiera cambiar por dentro la cabeza de un homófobo, un misógino o un nacionalista repleto de odio hacia los inmigrantes, sí podía transformar las condiciones de lo decible en el espacio común.

El panorama actual parece haber dado vuelta este asunto: en el nuevo orden global abundan políticos y candidatos que ganan elecciones llamando a la persecución de los inmigrantes, reenviando a las mujeres a sus antiguas tareas domésticas o

6. Ver Solnit, Rebecca, Wanderlust. Una historia del caminar, Hueders, 2015. 
condenando en calidad de perversas las decisiones libres de los cuerpos de cada quien. Para nadie resulta fácil comprender esta regresión, menos aún en un siglo que había nacido con marchas multitudinarias que venían a entrecomillar la mezquindad de las falsas democracias representativas. Tal vez merezca la pena, por lamentable que sea, invertir aquel diagnóstico realizado por Zizek y mencionar que todo lo que ya no puede ser dicho en la esfera pública, puede ser sin embargo votado.

No se trata del fin del mundo, pero a la vez es difícil no ser testigo a estas alturas de lo que la humanidad en su conjunto ha sido capaz de hacerse a sí misma. 


\section{REFERENCIAS}

Derrida, Jacques, Espectros de Marx, Trotta, 2012.

Lefort, Claude, La invención democrática, Nueva Visión, 1996.

Rancière, Jacques, El desacuerdo, Nueva Visión, 2007.

Auerbach, Erich, Mimesis. La representación de la realidad en la literatura occidental, FCE, 1986.

Thayer, Willy, La crisis no moderna de la universidad moderna, Cuarto Propio, 1996.

Solnit, Rebecca, Wanderlust. Una historia del caminar, Hueders, 2015. 